\title{
Blood Pressure Control among Adult African Chronic Kidney (CKD) Patients-How Close Are We to Target?
}

\author{
Effiong Ekong Akpan, Udeme Ekpenyong Ekrikpo, Aniema Isaac-Assam Udo, \\ Aniedi Victor Umoh, Idongesit Odudu Umoh
}

Department of Internal Medicine, University of Uyo, Uyo, Nigeria

Email: ffngakpan@yahoo.com, udemeekrikpo@uniuyo.edu.ng, aniodiong@yahoo.com, aaumoh@yahoo.com, aidee_a2@yahoo.com

How to cite this paper: Akpan, E.E., Ekrikpo, U.E., Udo, A.I.-A., Umoh, A.V. and Umoh, I.O. (2020) Blood Pressure Control among Adult African Chronic Kidney (CKD) Patients-How Close Are We to Target? Open Journal of Nephrology, 10, 50-59.

https://doi.org/10.4236/ojneph.2020.101007

Received: December 23, 2019

Accepted: March 21, 2020

Published: March 24, 2020

Copyright $\odot 2020$ by author(s) and Scientific Research Publishing Inc. This work is licensed under the Creative Commons Attribution International License (CC BY 4.0).

http://creativecommons.org/licenses/by/4.0/

\begin{abstract}
Background: Chronic kidney disease (CKD) is usually progressive, often resulting in end-stage renal disease (ESRD). The two most common causes of renal disease, hypertension and diabetes mellitus contribute greatly to the mobility and mortality associated with CKD. It has been found that lowering $\mathrm{BP}$ is effective in reducing cardiovascular events in patient with a moderate reduction in GFR and in those with ESRD on dialysis. The aim of this study was to assess blood pressure control among adult African CKD patients. Method: The case notes of chronic kidney patients who assess care in the renal unit of our Teaching Hospital were retrieved for the study after obtaining informed consent from the ethical unit of the hospital. To be eligible for the study, the patient, must have been attending the renal clinic and on anti-hypertensives for a minimum period of 6 months. Results: Eighty-seven CKD patients (46 males and 41 females) with a mean age of $50.9 \pm 13.3$ years. The proportion of patients who achieved blood pressure control was $13.79 \%$ (95\% CI 7.34\% - 22.85\%). Among the pre-dialysis patients, BP control was achieved in $13.64 \%$ compared to $14.29 \%$ among the patients on dialysis. Nineteen $(21.84 \%)$ of the patients were on one blood pressure lowering agent; $26(29.89 \%)$ on two; 33 (37.93\%) on three; 7 (8.05\%) on four and $2(2.30 \%)$ on five. Conclusion: Blood pressure control among African adult CKD patients is difficult with many of them requiring more than two antihypertensive drugs.
\end{abstract}

\section{Keywords}

Blood Pressure, Control. CKD, Africa 


\section{Introduction}

Chronic Kidney Disease (CKD) is progressive, often resulting in end-stage renal disease (ESRD). The high level of mobility and morbidity associated with CKD is well known. Measures such as normalization of hematocrit [1], use of high flux dialyzers for dialysis and, management of renal bone disease with calcimimetics have not been shown to reduce the adverse outcome associated with kidney disease [2] [3]. The lack of desirable outcome may be due to the underlying disease that led to renal disease. Blood pressure control is essential to the care of CKD patients regardless of the cause. The two most common causes of renal disease, hypertension and diabetes mellitus contribute significantly to the mobility and mortality associated with CKD. For instance, hypertension is a known cause of significant left ventricular hypertrophy in a third of patients on dialysis [4]. Left ventricular hypertrophy (LVH) is said to be an independent risk factor for death among chronic kidney disease patients [4]. It has been found that lowering BP is effective in lowering cardiovascular events in patients with moderate reduction in GFR and also in those with ESRD on dialysis [5].

Although studies have shown that strict control of blood pressure does not delay progression to ESRD [6] [7], it has however been shown that lower blood pressure (BP) may be associated with a lower risk of all-cause mortality after ESRD onset [8]. One randomized study has shown a significant reduction in the proportion of patients with coronary artery disease and congestive cardiac failure at the time of ESRD onset among patients randomized into strict BP control compared with those on usual BP control [8]. Systolic Blood Pressure Intervention Trial (SPRINT) [9] study also revealed that some patients with CKD may benefit from intensive BP lowering.

Though hypertension is associated with adverse outcome in patients undergoing dialysis, blood pressure target in dialysis has been controversial [10]. A U-shape relation has been found in systolic blood pressure (SBP) and mortality among patients undergoing haemodialysis, where the risk of mortality increases with lower SBP of $\leq 110 \mathrm{mmHg}$ and $\geq 170 \mathrm{mmHg}$ among older patients, having diabetes mellitus or coronary artery disease and younger patients respectively [11]. Others studies also confirm this association [10] [12] [13].

In a resource-poor economy such as ours, early identification and management of the risk factor of CKD remain the most viable option in reducing the mortality and morbidity associated with CKD. Therefore, treatment of our patients to the BP target of 130/80 mmHg should be our goal. The overarching aim of this study was to assess the frequency of hypertension control and determine independent factors associated with BP control adult among CKD patients

\section{Method}

The case notes of chronic kidney patients who access care in the renal unit of our Teaching Hospital were retrieved for the study after obtaining informed 
consent from the ethical unit of the hospital. The hospital is located in the oil-rich Niger-Delta of Nigeria, with an estimated population of about 6 million people [14]. Until recently, it was the only renal Centre in the whole state and also serves the neighboring states.

To be eligible for the study, the patients must have been attending the renal clinic and on anti-hypertensive for a minimum period of six months. Their sociodemographic data such as age, sex, educational status were recorded. They had their anthropometric measurements recorded. Height and weight were measured using standard weighing scale and Seca stadiometer. Their antihypertensive medications were also recorded. Only those who were on thrice weekly dialysis for six months were included in the study. They were examined to ensure that they had no peripheral oedma and their chest were also examined to ensure no fluid retention. Patients were group into five stages according to KIDGO (Kidney Disease: Improving Global Outcomes) [15]. For patients on dialysis, only those without peripheral oedema and with clinically clear chest on auscultation were included since the total fluid balance could not be measured. Estimated glomerular filtration rate (eGFR) was computed using the 4-variable modification of diet in renal disease (MDRD) equation [16]. Blood pressure was categorized using the 2017 ACC/AHA/AAPA/ABC/ACPM/AGS/APhA/ASH/ASPC/NMA/PCNA guideline for management of high blood pressure [17] while CKD staging was performed using the KDIGO classification [15].

Categorical data were presented as frequencies (and percentages) while continuous data were presented as means (and standard deviation), if normally distributed and as medians (and interquartile range) if skewed. The Student t-test was used to compare means between two groups. The prevalence of BP control was reported as percentage (and 95\% confidence interval). Univariable and multivariable logistic regression models were used to identify independent associations with BP control among our patient cohort.

\section{Results}

Eighty-seven CKD patients (46 males and 41 females) with a mean age of $50.9 \pm$ 13.3 years. Table 1 summarizes the characteristics of the CKD patients. There was no significant gender difference in the proportion of CKD patients with hypertension or having maintenance haemodialysis. The male patients were older.

Nineteen $(21.84 \%)$ of the patients were on one blood pressure lowering agent; $26(29.89 \%)$ on two; $33(37.93 \%)$ on three; 7 (8.05\%) on four and 2 $(2.30 \%)$ on five. Regarding type of antihypertensive used, the most commonly prescribed class (either as single agent or in combination) was the calcium channel blockers (73.03\%) followed by the diuretics (54.65\%); angiotensin-converting enzyme inhibitors $(51.16 \%)$; angiotensin receptor blockers (22.09\%); and alpha methyl-DOPA (32.56\%). No patient was routinely taking alpha-adrenergic blockers. Most $(86,98.85 \%)$ of the patients were adherent to their medications. 
Table 1. Characteristics of the study population.

\begin{tabular}{|c|c|c|c|c|}
\hline & Total $(\mathrm{N}=87)$ & Male $(n=46)$ & Female $(n=41)$ & $P$ \\
\hline Age (years) & $50.9 \pm 13.3$ & $54.8 \pm 14.4$ & $46.5 \pm 10.4$ & 0.003 \\
\hline \multicolumn{5}{|l|}{ CKD aetiology } \\
\hline $\mathrm{DM}$ & $27(31.03)$ & $13(28.26)$ & $14(34.15)$ & \multirow{5}{*}{0.34} \\
\hline CGN & $5(5.75)$ & $2(4.35)$ & $3(7.32)$ & \\
\hline HIV & $9(10.34)$ & $2(4.35)$ & $7(17.07)$ & \\
\hline Hypertension & $28(32.18)$ & $19(41.30)$ & $9(21.95)$ & \\
\hline Others & $18(20.70)$ & $10(21.74)$ & $8(19.51)$ & \\
\hline BMI & $26.51 \pm 5.80$ & $25.07 \pm 4.06$ & $27.80 \pm 6.86$ & 0.23 \\
\hline Serum sodium & $134.24 \pm 22.78$ & $133.78 \pm 21.71$ & $134.78 \pm 22.14$ & 0.84 \\
\hline Serum potassium & $4.61 \pm 0.88$ & $4.55 \pm 0.77$ & $4.68 \pm 0.99$ & 0.54 \\
\hline Serum chloride & $103.14 \pm 6.98$ & $100.70 \pm 7.04$ & $105.99 \pm 5.80$ & $<0.001$ \\
\hline Serum bicarbonate & $21.23 \pm 4.18$ & $21.13 \pm 4.04$ & $21.34 \pm 4.39$ & 0.84 \\
\hline Proportion on dialysis & $21(24.14)$ & $11(23.91)$ & $10(24.39)$ & 0.96 \\
\hline \multicolumn{5}{|l|}{ Blood pressure stages } \\
\hline Normal & $2(2.30)$ & $0(0.00)$ & $2(4.88)$ & \multirow{4}{*}{0.34} \\
\hline Elevated & $1(1.15)$ & $1(2.17)$ & $0(0.00)$ & \\
\hline Stage 1 & $10(11.49)$ & $6(13.04)$ & $4(9.76)$ & \\
\hline Stage 2 & $74(85.06)$ & $35(85.37)$ & $39(84.78)$ & \\
\hline Serum creatinine & $240(141-504)$ & $245(156-476)$ & $221(109-509)$ & 0.41 \\
\hline \multicolumn{5}{|l|}{ CKD stage } \\
\hline 1 & $8(9.20)$ & $2(4.35)$ & $6(14.63)$ & \\
\hline 2 & $12(13.79)$ & $6(13.04)$ & $6(14.63)$ & \\
\hline 3 & $27(31.03)$ & $16(34.78)$ & $11(26.83)$ & \\
\hline 4 & $17(19.54)$ & $11(23.91)$ & $6(14.63)$ & \\
\hline 5 & $23(26.44)$ & $11(23.91)$ & $12(29.27)$ & \\
\hline
\end{tabular}

$\mathrm{CKD}=$ chronic kidney disease; $\mathrm{DM}=$ diabetes mellitus; $\mathrm{CGN}=$ chronic glomerulonephritis; $\mathrm{HIV}=$ human immunodeficiency virus; $\mathrm{BMI}=$ body mass index.

\subsection{Frequency of Blood Pressure Control}

The proportion of patients who achieved blood pressure control was $13.79 \%$ (95\% CI 7.34\% - 22.85\%). There was no significant gender difference in blood pressure control (12.20\% among females versus $15.22 \%$ among males, $p=0.68$ ). Among the pre-dialysis patients, BP control was achieved in $13.64 \%$ (95\% CI $6.42 \%-24.31 \%)$ compared to $14.29 \%(3.04 \%-36.34 \%)$ among the patients on dialysis, $p=0.94$.

\subsection{Associations with Blood Pressure Control}

Table 2 summarizes the factors that were independently associated with blood pressure control within the first 6 months of initiation of blood pressure-lowering 
Table 2. Independent associations with blood pressure control.

\begin{tabular}{lcc}
\hline & $\begin{array}{c}\text { Univariable models } \\
\text { OR }(95 \% \mathrm{CI}) \mathrm{p} \text {-value }\end{array}$ & $\begin{array}{c}\text { Multivariable models } \\
\text { OR }(95 \% \mathrm{CI}) \mathrm{p} \text {-value }\end{array}$ \\
\hline Age (years) & $1.02(0.98-1.07) 0.34$ & $1.03(0.91-1.17) 0.61$ \\
Male gender & $1.29(0.38-4.44) 0.68$ & $1.63(0.08-31.77) 0.75$ \\
Initial mABP (mmHg) & $0.76(0.64-0.90) 0.001$ & $0.69(0.52-0.92) 0.01$ \\
Number of BP medications & $0.41(0.19-0.90) 0.02$ & $0.90(0.16-5.06) 0.90$ \\
Presence of DM & $1.98(0.40-9.81) 0.40$ & $13.13(0.45-381.86) 0.13$ \\
CKD stage & 1 & 1 \\
1 & $1.00(0.13-7.89) 0.99$ & $0.11(0.001-12.57) 0.37$ \\
2 & $0.38(0.05-2.77) 0.34$ & $0.37(0.003-36.45) 0.67$ \\
3 & $0.40(0.04-3.53) 0.41$ & $0.04(0.001-10.86) 0.27$ \\
4 & $0.29(0.03-2.48) 0.26$ & $0.06(0.001-4.96) 0.22$ \\
\hline
\end{tabular}

$\mathrm{BP}=$ blood pressure; $\mathrm{DM}=$ diabetes mellitus; eGFR = estimated glomerular filtration rate. The area under the receiver operator characteristic curve for the final model was 0.78 .

agents. Initial systolic blood pressure and eGFR were independently associated with blood pressure control.

\section{Discussion}

Hypertension is common among patients with CKD, notwithstanding the cause [18]. Blood pressure control is therefore essential in patients with CKD. This study was based on KIDGO [15] recommendation of blood pressure $\leq 130 / 80$ $\mathrm{mm} \mathrm{Hg}$ for patients with chronic kidney disease with moderately or severely increased albuminuria. Although albuminuria was not quantified in our patients all of them presented with overt proteinuria. The control of hypertension in CKD patients has also been shown to be generally very poor as low as $16.3 \%$ to $40 \%$ [10]. Our study was not different has only $13.79 \%$ (95\% CI 7.34\% - 22.85\%) were controlled despite $98.85 \%$ drugs adherence. It has been shown that $21.8 \%$ of adult with hypertension and CKD in a population-based study had apparent resistant hypertension [19]. Among the pre-dialysis patients, BP control was achieved in $13.64 \%$ (95\% CI $6.42 \%-24.31 \%$ ) compared to $14.29 \%(3.04 \%$ $36.34 \%$ ) among the patients on dialysis. This noticeable different though not statistically significant may be because of fluid management in patients on dialysis as most them were able to achieve dry-weight. It has been found that where long dialysis and strict salt control is applied hypertension has lower prevalence among dialysis patients [11] [20].

Hypertension in dialysis is multifactorial but sodium and water excess appear to be the major causes [11] [12]. Most of the patients were on sodium restriction.

Target blood pressure in haemodialysis patients has been controversial. However it has been observed that SBP may be more important than DBP [11]. Some studies have shown a U-shape relationship between SBP and mortality among 
patients undergoing haemodialysis. [11] [12] [13]. It has also been shown that the risk of mortality increases with lower SBP of $\leq 110 \mathrm{mmHg}$ for older and diabetic patients and $\geq 170 \mathrm{mmHg}$ for younger patients [11]. However we aimed at lower blood pressure because most of our patients were younger with an average age of $50.9 \pm 13.3$.

Non-pharmacological and pharmacological measures should be applied in management of blood pressure among dialysis patients. The non-pharmacological measures should aim at reducing sodium and volume excess, achievement of dry-weight, minimizing inter-and intra-dialysis sodium again and avoidance of short duration of dialysis of less than 4 hours [11] [20]

The commonest prescribed medication was calcium blocker plus a diuretic, followed by angiotensin receptor blocker plus diuretic. This was similar to the previous study in Benin City [21]. The Calcium chanel blocker, Amlodipine, was found to reduce cardiovascular events compared with placebo in HD patients with hypertension in a study [22]. Another commonly prescribed medication in our study was alpha methyl dopa and angiotensin receptor blocker. A combination of diuretic and calcium channel blocker was frequently combined medication. This may be because hypertension in the black is said to be a result of volume overload and these drugs appear to be more affordable than most other anti-hypertensive. More so, this is in conjunction with the Eight Joint National Committee Guidelines on Prevention, Detection, Evaluation and Treatment of High Blood Pressure (JNC 8). It has also been found that calcium channel blocker and diuretic lower blood pressure than $\beta$-blockers and RAS blockers in blacks when used as monotherapies [23]. However, most of the patients were on a combination of two or more drugs. Many randomized controlled trials and subsequent systematic reviews have shown that the beneficial effects of antihypertensive medications are due to the blood pressure lowering effects independent of the class of antihypertensive [24]. Another commonly prescribed medication was the Angiotensin-converting enzyme inhibitors (ACEI) either in combination with a diuretic or Calcium channel blockers (CCBs). Avoiding Cardiovascular Events through Combination Therapy in Patients Living with Systolic Hypertension (ACCOMPLISH) trial did demonstrate that the combination of ACE inhibitors and calcium channel blockers was effective in preventing the doubling of creatinine and end-stage disease, although not effective in preventing proteinuria [25]. Most of patients were on calcium channel blocker and ACE inhibitors. The Reno protective effects of ACE inhibitors and angiotensin receptor blockers are well established [26].

About $21.84 \%$ of patients were on monotherapy, this was slightly higher than $17.8 \%$ in a previous study in Benin on the prescription pattern of antihypertensive [20]. About 53.6\% were controlled to target in their study whereas, in our study, only $13.79 \%$ were on target. This may be because our study was undertaken among chronic kidney disease individuals. Blood pressure control in chronic kidney disease is more difficult than hypertensives who do not have CKD. Kidney Disease: Improving Global Outcomes (KDIGO) [15] guideline for blood 
pressure management in patients with chronic kidney disease not on dialysis recommend a blood pressure of $\leq 140 / 90 \mathrm{mmHg}$ for non-dialysis patients with normal or mildly increased albuminuria $(<30 \mathrm{mg} / 24 \mathrm{hrs})$ for both diabetic and non-diabetic. Those with moderately (30 - $300 \mathrm{mg} / 24 \mathrm{hrs)}$ or severely increased albuminuria ( $>300 \mathrm{mg} / 24 \mathrm{hrs}$ ) KDIGO continue to recommend a blood pressure of $\leq 130 / 80 \mathrm{mmHg}$. We choose blood pressure of $130 / 80 \mathrm{mmHg}$ because all our patients presented late with overt proteinuria.

We have discovered that most of our patients required more than one antihypertensive drug to achieved control. Most of them were on three drugs combination. It has been found that $50 \%-70 \%$ of patients will require the combination of two or more drugs to achieved target BP control. [21]. Joint National Committee on Prevention, Detection, Evaluation, and Treatment of High Blood Pressure (JNC7) [27] recommend the use of multiple drugs for control of BP in those with hypertension and those with higher BP and greater risk. Especially those with $\mathrm{BP}>20 / 10 \mathrm{~mm} \mathrm{Hg}$ above their target. Most patients in this study were in stages 2 and above (Table 1). Previous studies in Nigeria were in support of our findings [19] [28] [29]. The small sample size in this study is largely as a result of poor access to specialist care and also because most of the patients seen in our clinic had poor drugs compliance and therefore were not eligible for the study. This is because most of them couldn't afford the medications especially those on dialysis due to lack of funds as they often had to pay from their pocket. Government should strengthen the existing national health insurance scheme to include every citizen for better health care delivery.

\section{Limitations}

Fluid balance of those on dialysis was not objectively assessed. We relied on the clinical examination alone. This may have affected the blood pressure control in this cohort of patients.

The sample size was small therefore study with a large sample size is recommended.

\section{Conclusion}

Blood pressure control among our CKD patients is still not up to target. Combination of two or more antihypertensive drugs should be initiated early in management.

\section{Conflicts of Interest}

The authors declare no conflicts of interest regarding the publication of this paper.

\section{References}

[1] Besarab, A., Bolton, W.K., Browne, J.K., et al. (1998) The Effects of Normal as Compared with Low Hematocrit Values in Patients with Cardiac Disease Who Are Receiving Hemodialysis and Epoetin. The New England Journal of Medicine, 339, 
584-590. https://doi.org/10.1056/NEJM199808273390903

[2] Eknoyan, G., Beck, G.J., Cheung, A.K., et al. (2002) Effect of Dialysis Dose and Membrane Flux in Maintenance Hemodialysis. The New England Journal of Medicine, 347, 2010-2019. https://doi.org/10.1056/NEJMoa021583

[3] Paniagua, R., Amato, D., Vonesh, E., et al. (2002) Effects of Increased Peritoneal Clearances on Mortality Rates in Peritoneal Dialysis: ADEMEX, a Prospective, Randomized, Controlled Trial. Journal of the American Society of Nephrology, 13, 1307-1320.

[4] Foley, R.N., Parfrey, P.S., Harnett, J.D., et al. (1995) Clinical and Echocardiographic Disease in Patients Starting End-Stage Renal Disease Therapy. Kidney International, 47, 186-192. https://doi.org/10.1038/ki.1995.22

[5] Ninomiya, T., Perkovic, V., Turnbull, F., et al. (2013) Blood Pressure Lowering and Major Cardiovascular Events in People with and without Chronic Kidney Disease: Meta-Analysis of Randomized Controlled Trials. BMJ, 347, F5680. https://doi.org/10.1136/bmj.f5680

[6] Elaine, K., David, V.G., Kirsten, L.J., Mark, S., Hocine, T., Barbara, G. and Chi-yuan, H. (2015) Association between Strict Blood Pressure Control during Chronic Kidney Disease and Lower Mortality after Onset of End-Stage Renal Disease. Kidney International, 87, 1055-1060. https://doi.org/10.1038/ki.2014.376

[7] Wright, J.T., Bakris, G., Greene, T., et al. (2002) Effect of Blood Pressure Lowering and Antihypertensive Drug Class on Progression of Hypertensive Kidney Disease: Results from the AASK Trial. JAMA, 288, 2421-2431.

https://doi.org/10.1001/jama.288.19.2421

[8] Ruggenenti, P., Perna, A., Loriga, G., et al. (2005) Blood-Pressure Control for Renoprotection in Patients with Non-Diabetic Chronic Renal Disease (REIN-2): Multicentre, Randomised Controlled Trial. The Lancet, 365, 939-946.

https://doi.org/10.1016/S0140-6736(05)71082-5

[9] The Sprint Research Group (2015) A Randomized Trial of Intensive versus Standard Blood Pressure Control. The New England Journal of Medicine, 373, 2103-2116. https://doi.org/10.1056/NEJMoa1511939

[10] Jhee, J.H., Park, J., Kim, H., et al. (2018) The Optimal Blood Pressure Target in Different Dialysis Populations. Scientific Reports, 8, Article No. 1412. https://doi.org/10.1038/s41598-018-32281-w

[11] Sarafidis, P.A., Persu, A., et al. (2017) Hypertension in Dialysis Patients: A Consensus Document by the European Renal and Cardiovascular Medicine (EURECA-m) Working Group of the European Renal Association-European Dialysis and Transplant Association (ERA-EDTA) and the Hypertension and the Kidney Working Group of the European Society of Hypertension (ESH). Nephrology Dialysis Transplantation, 32, 620-640. https://doi.org/10.1093/ndt/gfw433

[12] McCallum, W. and Sarnak, M.J. (2019) Blood Pressure Target for the Dialysis Patient. Seminars in Dialysis, 32, 35-40. https://doi.org/10.1111/sdi.12754

[13] Myers, O.B., Adams, C., Rohrscheib, M.R., et al. (2010) Age, Race, Diabetes, Blood Pressure, and Mortality among Hemodialysis Patients. American Society of Nephrology, 21, 1970-1978. https://doi.org/10.1681/ASN.2010010125

[14] National Population Commission of Nigeria (Web), National Bureau of Statistics (Web).

[15] Kidney Disease: Improving Global Outcomes (KDIGO) Blood Pressure Work Group (2012) KDIGO Clinical Practice Guideline for the Management of Blood Pressure in Chronic Kidney Disease. Kidney International, 2, 337-414. 
[16] Levey, A.S., Bosch, J.P., Lewis, J.B., Greene, T., Rogers, N. and Roth, D. (1999) A More Accurate Method to Estimate Glomerular Filtration Rate from Serum Creatinine: A New Prediction Equation. Modification of Diet in Renal Disease Study Group. Annals of Internal Medicine, 130, 461-470. https://doi.org/10.7326/0003-4819-130-6-199903160-00002

[17] Wheaton, P.K., Carey, R.M., Aronow, W.S., Casey Jr., D.E., Karen, J., et al. (2018) ACC/AHA/AAPA/ABC/ACPM/AGS/APhA/ASH/ASPC/NMA/PCNA Guideline for the Prevention, Detection, Evaluation, and Management of High Blood Pressure in Adults: A Report of the American College of Cardiology/American Heart Association Task Force on Clinical Practice Guidelines. Hypertension, 71, e13-e115. https://doi.org/10.1016/j.jacc.2017.11.006

[18] Altun, B., Süleymanlar, G., Utaş, C., Arınsoy, T., Ateş, K., Ecder, T., Camsarı, T. and Serdengeçti, K. (2012) Prevalence, Awareness, Treatment and Control of Hypertension in Adults with Chronic Kidney Disease in Turkey: Results from the CREDIT Study. Kidney and Blood Pressure Research, 36, 36-46. https://doi.org/10.1159/000339025

[19] Tanner, R.M., Calhoun, D.A., Bell, E.K., et al. (2013) Prevalence of Apparent Treatment-Resistant Hypertension among Individuals with CKD. Clinical Journal of the American Society of Nephrology, 8, 1583-1590. https://doi.org/10.2215/CJN.00550113

[20] Tattersall, J., Martin-Malo, A., Pedrini, L., et al. (2007) EBPG Guideline on Dialysis Strategies. Nephrology Dialysis Transplantation, 22, ii5-ii21.

https://doi.org/10.1093/ndt/gfm022

[21] Adejumo, O., Okaka, E. and Iyawe, I. (2017) Prescription Pattern of Antihypertensive Medications and Blood Pressure Control among Hypertensive Outpatients at the University of Benin Teaching Hospital in Benin City, Nigeria. Malawi Medical Journal, 29, 113-117. https://doi.org/10.4314/mmj.v29i2.7

[22] Tepel, M., Hopfenmueller, W., Scholze, A., et al. (2008) Effect of Amlodipine on Cardiovascular Events in Hypertensive Haemodialysis Patients. Nephrology Dialysis Transplantation, 23, 3605-3612. https://doi.org/10.1093/ndt/gfn304

[23] Douglas, J.G., Bakris, G.L., Epstein, M., Ferdinand, K.C., Ferrario, C., Flack, J.M., Jamerson, K.A., Jones, W.E., Haywood, J., Maxey, R., Ofili, E.O., Saunders, E., Schiffrin, E.L., Sica, D., Sowers, J.R. and Vidt, D.G. (2003) Management of High Blood Pressure in African Americans: A Consensus Statement of the Hypertension in African Americans Working Group of the International Society on Hypertension in Blacks. Archives of Internal Medicine, 163, 525-541.

https://doi.org/10.1001/archinte.163.5.525

[24] Thomopoulous, C., Parati, G. and Zanchetti, A. (2015) Effects of Blood Pressure Outcome Incidence in Hypertension. 4. Effects of Various Classes of Antihypertensive Drugs-Overview and Meta-Analyses. Journal of Hypertension, 33, 195-211. https://doi.org/10.1097/HJH.0000000000000447

[25] Bakris, G., Sarafidis, P.A., Weir, M.R., et al. (2010) Renal Outcomes with Different Fixed-Dose Combination Therapies in Patients with Hypertension at High Risk of Cardiovascular Event (Accomplish): A Prespecified Secondary Analysis of Randomized Controlled Trial. The Lancet, 375, 1173-1181. https://doi.org/10.1016/S0140-6736(09)62100-0

[26] Hsu, T.W., Liu, J.S., Hung, S.C., et al. (2014) Renoprotective Effect of Renin-Angiotensin-Aldosterone System Blockade in Patients with Predialysis Advanced Chronic Kidney Disease, Hypertension, and Anemia. JAMA Internal Medicine, 174, 347-354. https://doi.org/10.1001/jamainternmed.2013.12700 
[27] Chobanian, A.V., Bakris, G.L., Black, H.R., et al. (2003) The National High Blood Pressure Education Program Coordinating Committee. Seventh Report of the Joint National Committee on Prevention, Detection, Evaluation, and Treatment of High Blood Pressure. Hypertension, 42, 1206-1252. https://doi.org/10.1161/01.HYP.0000107251.49515.c2

[28] Busari, O.A., Olanrewaju, T.O., Desalu, O.O., Opadijo, G.O., Jimoh, A.K., Agboola, S.M., et al. (2010) Impact of Knowledge, Attitude and Practices on Hypertension on Compliance with Antihypertensive in a Resource-Poor Setting. TAF Preventive Medicine Bulletin, 9, 87-92.

[29] Busari, O.A., Oluyombo, R., Fasae, A.J., Gabriel, E.O., Ayodele, L.M., Agboola, S.M., et al. (2014) Prescribing Pattern and Utilization of Antihypertensive Drugs and Blood Pressure Control in Adults Patients with Systemic Hypertension in a Rural Tertiary Hospital in Nigeria. American Journal of Internal Medicine, 2, 144-149. https://doi.org/10.11648/j.ajim.20140206.18 